University of Wollongong

Research Online

Faculty of Engineering - Papers (Archive)

Faculty of Engineering and Information

Sciences

2012

\title{
Alpha particle and proton relative thermoluminescence efficiencies in LIF:MG,CU,P:IS track structure theory up to the task?
}

\author{
Y S. Horowitz \\ University of the Negev, Beersheva, Israel \\ D Siboni \\ University of the Negev, Beersheva, Israel \\ L Oster \\ Sami Shamoon College of Engineering, Beersheva, Israel \\ J Livingstone \\ University of Wollongong, jayde@uow.edu.au \\ S Guatelli \\ University of Wollongong, susanna@uow.edu.au
}

See next page for additional authors

Follow this and additional works at: https://ro.uow.edu.au/engpapers

Part of the Engineering Commons

https://ro.uow.edu.au/engpapers/4854

\section{Recommended Citation}

Horowitz, Y S.; Siboni, D; Oster, L; Livingstone, J; Guatelli, S; Rosenfeld, Anatoly B.; Emfietzoglou, D; Bilski, $\mathrm{P}$; and Obryk, B: Alpha particle and proton relative thermoluminescence efficiencies in LIF:MG,CU,P:IS track structure theory up to the task? 2012, 359-374.

https://ro.uow.edu.au/engpapers/4854

Research Online is the open access institutional repository for the University of Wollongong. For further information contact the UOW Library: research-pubs@uow.edu.au 
Authors

Y S. Horowitz, D Siboni, L Oster, J Livingstone, S Guatelli, Anatoly B. Rosenfeld, D Emfietzoglou, P Bilski, and B Obryk

This journal article is available at Research Online: https://ro.uow.edu.au/engpapers/4854 


\section{ALPHA PARTICLE AND PROTON RELATIVE THERMOLUMINESCENCE EFFICIENCIES IN LIF:MG,CU,P:IS TRACK STRUCTURE THEORY UP TO THE TASK?}

Y. S. Horowitz ${ }^{1, *}$, D. Siboni ${ }^{1}$, L. Oster ${ }^{2}$, J. Livingstone ${ }^{3}$, S. Guatelli ${ }^{3}$, A. Rosenfeld ${ }^{3}$, D. Emfietzoglou ${ }^{4}$, P. Bilski ${ }^{5}$ and B. Obryk ${ }^{5}$

${ }^{1}$ Physics Department, Ben Gurion University of the Negev, Beersheva, Israel

${ }^{2}$ Physics Unit, Sami Shamoon College of Engineering, Beersheva, Israel

${ }^{3}$ Center for Medical Radiation Physics, University of Wollongong, Wollongong, Australia

${ }^{4}$ Department of Medical Physics, University of Ioannina Medical School, Ioannina, Greece

${ }^{5}$ Institute of Nuclear Physics, Polish Academy of Sciences, Radzikowskiego 152, 31-342 Krakow, Poland

*Corresponding author: yigal@bgu.ac.il or yigalho@gmail.com

Received July 13 2011, revised September 22 2011, accepted September 222011

Low-energy alpha particle and proton heavy charged particle (HCP) relative thermoluminescence (TL) efficiencies are calculated for the major dosimetric glow peak in LiF:Mg, Cu,P (MCP-N) in the framework of track structure theory (TST). The calculations employ previously published TRIPOS-E Monte Carlo track segment values of the radial dose in condensed phase LiF calculated at the Instituto National de Investigaciones Nucleares (Mexico) and experimentally measured normalised ${ }^{60} \mathrm{Co}$ gamma-induced TL dose-response functions, $f(D)$, carried out at the Institute of Nuclear Physics (Poland). The motivation for the calculations is to test the validity of TST in a TL system in which $f(D)$ is not supralinear $(f(D)>1)$ and is not significantly dependent on photon energy contrary to the behaviour of the dose-response of composite peak 5 in the glow curve of LiF:Mg,Ti (TLD-100). The calculated HCP relative efficiencies in LiF:MCP-N are 23-87 \% lower than the experimentally measured values, indicating a weakness in the major premise of TST which exclusively relates HCP effects to the radiation action of the secondary electrons liberated by the HCP slowing down. However, an analysis of the uncertainties involved in the TST calculations and experiments (i.e. experimental measurement of $f(D)$ at high levels of dose, sample light self-absorption and accuracy in the estimation of $D(r)$, especially towards the end of the HCP track) indicate that these may be too large to enable a definite conclusion. More accurate estimation of sample light self-absorption, improved measurements of $f(D)$ and full-track Monte Carlo calculations of $D(r)$ incorporating improvements of the low-energy electron transport are indicated in order to reduce uncertainties and enable a final conclusion.

\section{INTRODUCTION}

\section{Preamble}

The calculation of heavy charged particle (HCP) relative thermoluminescence (TL) efficiencies using track structure theory (TST) is important for the accurate dosimetry of complex/mixed radiation fields in order to establish a sound theoretical basis for the applied techniques and aid in the interpretation and analysis of dosimetric data. A major assumption of TST is that the radiation effects of high-linear energy transfer (LET) HCPs arise exclusively from the contribution of the secondary and higher order electrons generated by the HCP slowing down. Direct atomic displacements arising from $\mathrm{HCP}$ nucleus elastic scattering, which lead to the enhanced creation of $\mathrm{F}$ centres and other defects and to the possible alteration of the TL mechanisms, are assumed to have a negligible effect compared with the radiation action of the ejected secondary electrons. The validity of this major premise of TST has yet to be fully established in TL systems and the application of TST to HCP radiation effects in $\mathrm{LiF}: \mathrm{MCP}$ is the subject of this paper.

\section{Dosimetric characteristics of LiF:MCP and LiF:Mg,Ti}

Two families of LiF materials are widely used in dosimetric applications. The first, $\mathrm{LiF}: \mathrm{Mg}$, Ti, discovered in the $1950 \mathrm{~s}$, is doped with $\sim 100 \mathrm{ppm} \mathrm{Mg}$ and $\sim 10$ ppm $\mathrm{Ti}$ and was developed commercially and patented by the Harshaw Chemical Co. as TLD-100 in 1963. The second, $\mathrm{LiF}: \mathrm{Mg}, \mathrm{Cu}, \mathrm{P},(\mathrm{LiF}: \mathrm{MCP})$ was discovered in the $1970 \mathrm{~s}$, is doped with $\mathrm{Mg}(0.2 \mathrm{M} \%)$, $\mathrm{Cu}(1.25 \mathrm{M} \%)$ and $\mathrm{P}(0.05 \mathrm{M} \%)$ and is identified as MCP-N in one of its commercial 'standard' forms manufactured by the Institute of Nuclear Physics in Poland. Other variations of these two materials are also available from other manufacturers. The two materials have several very different TL characteristics leading to various advantages and disadvantages 


\section{Y. S. HOROWITZ ET AL.}

in dosimetric applications ${ }^{(1,2)}$. $\mathrm{LiF}: \mathrm{MCP}$ is $\sim 20-50$ times more sensitive to gamma rays than $\mathrm{LiF}: \mathrm{Mg}$, $\mathrm{Ti}$ and both materials have a dominant glow peak (labelled peak 5 in LiF:Mg,Ti and peak 4 in LiF:MCP) following low-LET photon/electron radiation whose maximum intensity $\left(T_{\max }\right)$ occurs at $\sim 210^{\circ} \mathrm{C}$ when measured at a glow curve heating rate of $1^{\circ} \mathrm{C} \mathrm{s}^{-1}$. First-order kinetic analysis yields an anomalously

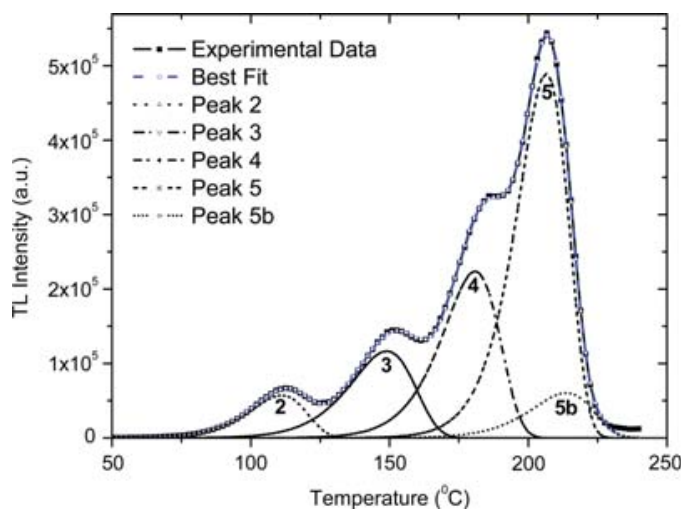

Figure 1. Glow curve of $\mathrm{LiF}: \mathrm{Mg}, \mathrm{Ti}$ following ${ }^{90} \mathrm{Sr} /{ }^{90} \mathrm{Y}$ beta-ray irradiation to a dose level of $0.1 \mathrm{~Gy}$. All glow curves shown in this paper were accumulated using a linear heating rate of $1^{\circ} \mathrm{C} \mathrm{s}^{-1}$. high activation energy of $\sim 2-2.3 \mathrm{eV}$ for both glow peaks. The main difference in the glow curve structure between the two materials, following low-LET radiation at low levels of dose, is the significantly reduced intensity of the lower temperature peaks 2 and 3 and the lack of a lower temperature satellite (peak 4) to composite peak 5 which is present in the glow curve of $\mathrm{LiF}: \mathrm{Mg}, \mathrm{Ti}$ but not present in LiF:MCP (Figures 1 and 2). With HCP irradiation such as protons and alpha particles of energy $\sim 1$ $\mathrm{MeV} \mathrm{amu}{ }^{-1}$, both glow curves exhibit a high-temperature structure composed of several glow peaks with again much lower intensities relative to the main peak. For $\mathrm{LiF}: \mathrm{Mg}, \mathrm{Ti}$ irradiated by $5-\mathrm{MeV}$ alpha particles, the intensity of the high-temperature structure is $\sim 50 \%$ of the peak-height intensity of peak 5 compared with $\sim 5 \%$ following low-LET irradiation at $\sim 0.1$ Gy (Figure 3). The evolution of the LiF:Mg,Ti glow curve as a function of dose for low-LET irradiation is shown in Figure 4. The high-temperature structure increases in relative intensity due to its strong supralinear dose-response; the glow curve following alpha-particle irradiation can be seen to be similar to the glow curve following low-LET irradiation at a dose level of $\sim 4000 \mathrm{~Gy}$. This behaviour is easily explained in TST since the radial dose following alpha-particle irradiation decreases from $\sim \mathrm{MGy}$ near the track axis to $\sim$ zero over radial distances of

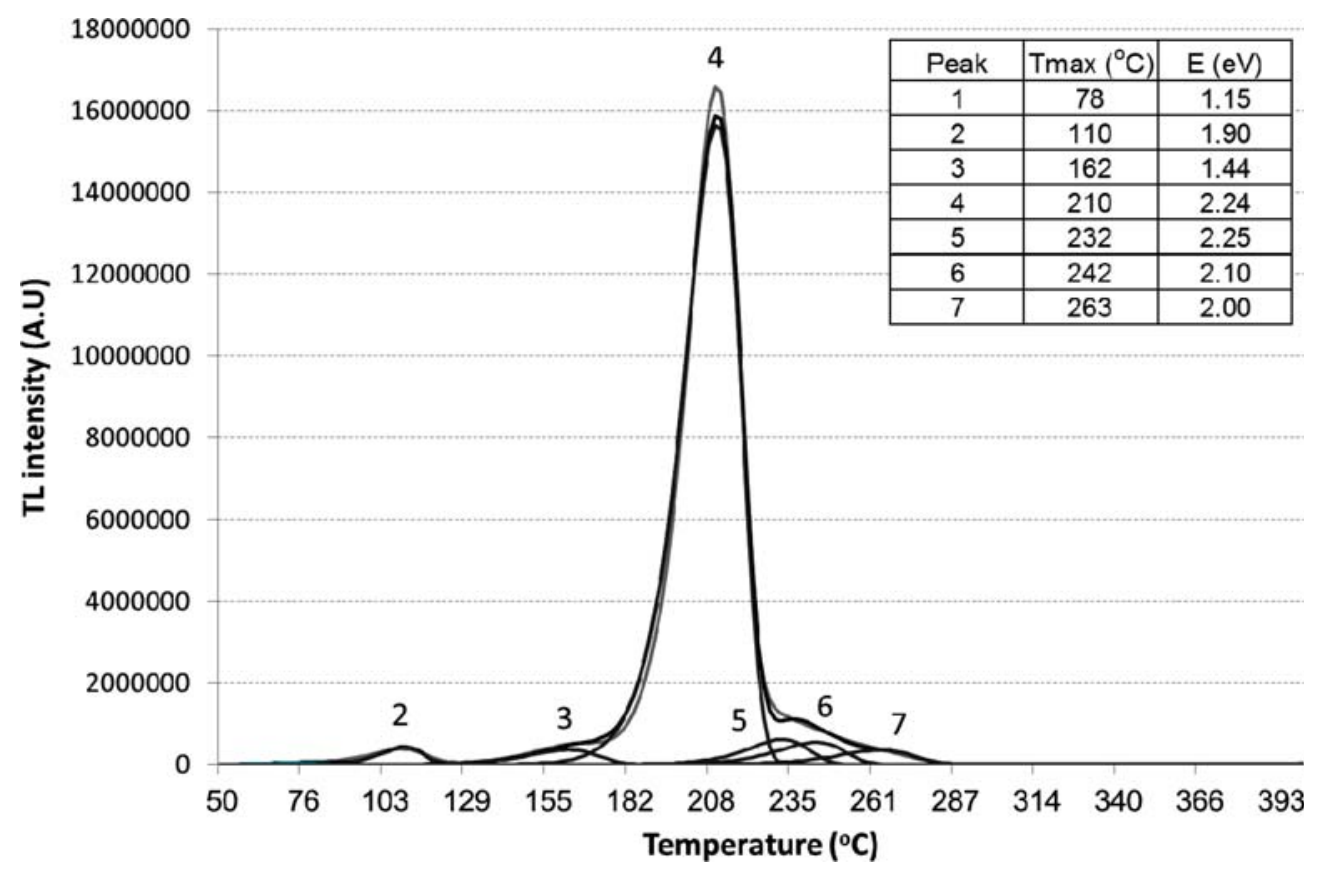

Figure 2. Glow curve of $\mathrm{LiF}: \mathrm{Mg}, \mathrm{Cu}, \mathrm{P}$ following ${ }^{60} \mathrm{Co}$ gamma irradiation to a dose level of 0.1 Gy. Note the greatly reduced intensity of the low-temperature peaks and the apparent absence of the low-temperature shoulder of the main peak (peak 4 in LiF:Mg,Ti). 
$\sim 100 \mathrm{~nm}$. The alpha-particle glow curve when volume averaged over these levels of radial dose results in a glow curve similar to the low-LET glow

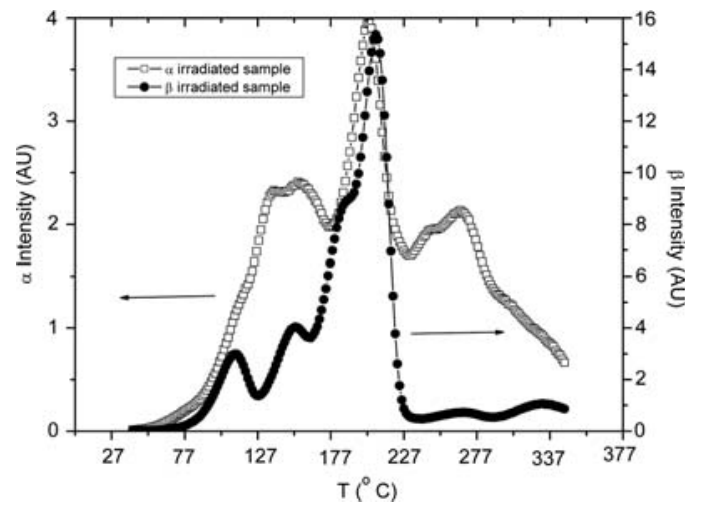

Figure 3. Glow curve of $\mathrm{LiF}: \mathrm{Mg}$, Ti following high-LET ${ }^{241} \mathrm{Am}$ alpha-particle irradiation and low-LET ${ }^{90} \mathrm{Sr} /{ }^{90} \mathrm{Y}$ betaray irradiation, normalised to equal intensities of peak 5 . curve at $\sim 4000$ Gy. The general features of this behaviour are also seen in LiF:MCP, although the high-temperature structure is less pronounced following alpha-particle irradiation (Figure 5) when compared with the LiF:MCP-N glow curve induced by 5000-Gy low-LET irradiation (Figure 6). These similarities in the glow curve structure and behaviour for different values of LET can certainly be taken to indicate some shared features in the TL mechanisms in the two materials. On the other hand, the greatly reduced relative intensities of both the low- and hightemperature glow peaks and the differences in thermal and dose-response indicate very significant alterations or even different trapping structures in the two materials. LiF: $\mathrm{Mg}$, Ti must be annealed at $400^{\circ} \mathrm{C}$ for repeated use following high-dose irradiation and can withstand even higher temperatures without damage, whereas LiF:MCP cannot be annealed or readout at temperatures exceeding $240^{\circ} \mathrm{C}$ without incurring a permanent loss in sensitivity. In $\mathrm{LiF}: \mathrm{Mg}, \mathrm{Ti}$, peak 4 is believed to arise from a singly trapped hole in the spatially correlated trapping
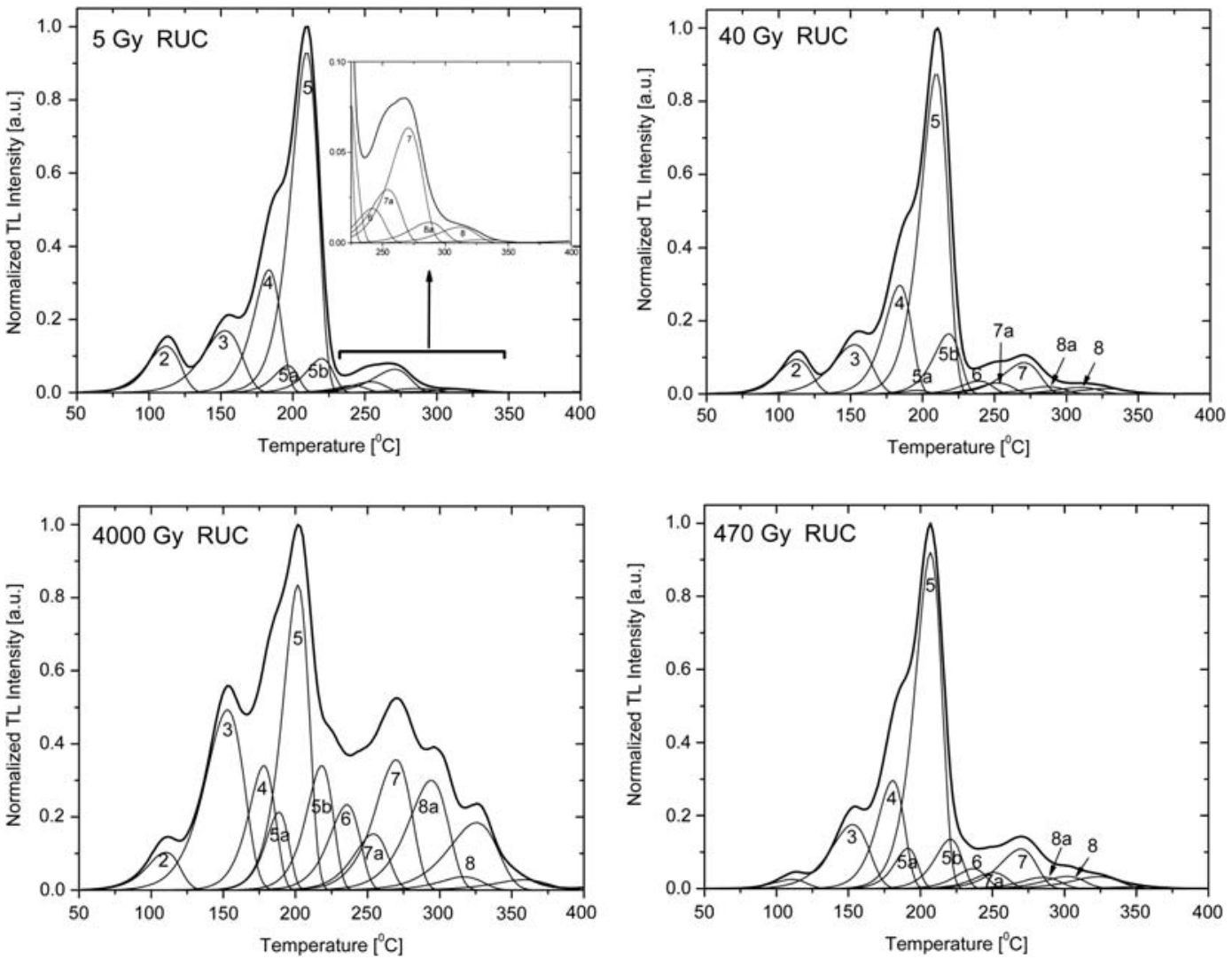

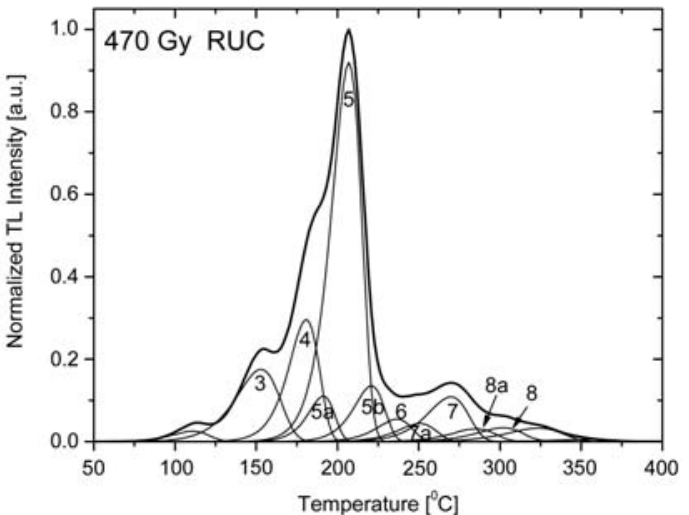

Figure 4. Glow curve of LiF:Mg, Ti following ${ }^{90} \mathrm{Sr} /{ }^{90} \mathrm{Y}$ beta-ray irradiation at four levels of dose from 5 to $4000 \mathrm{~Gy}$. RUC refers to the cooling rate following the $400^{\circ} \mathrm{C}$ pre-irradiation annealing (rapid uncontrolled cooling, i.e. removal of the chip from the furnace and transfer to a ceramic plate). 


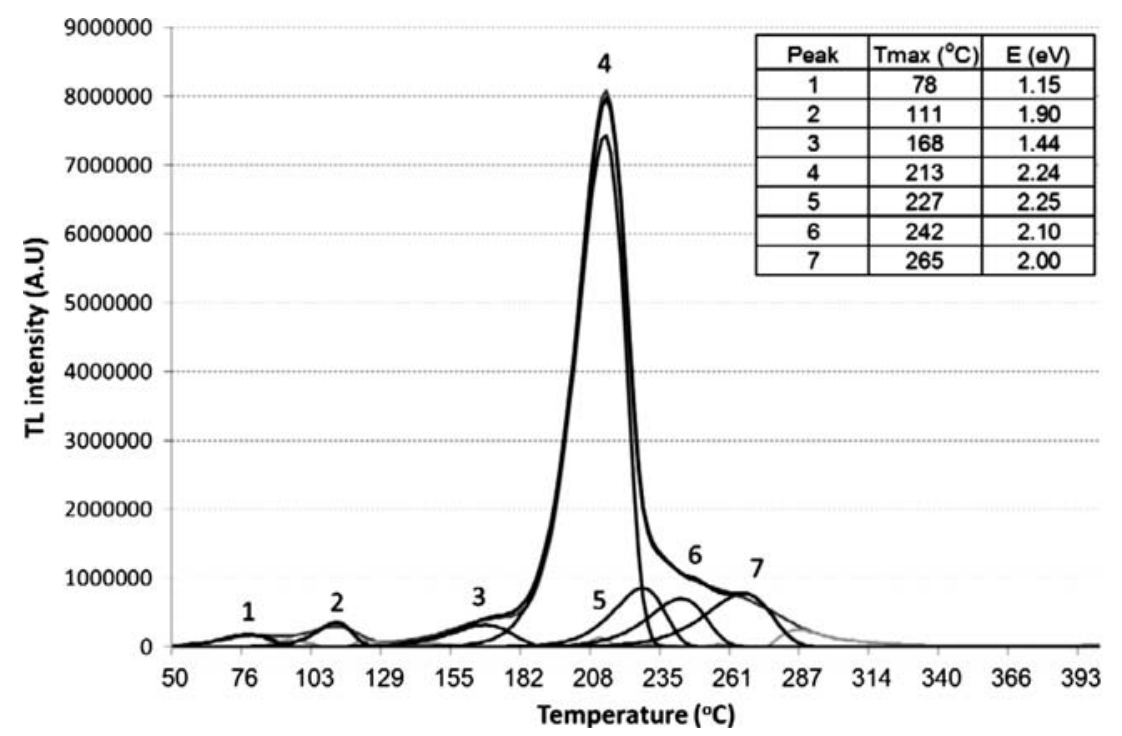

Figure 5. Glow curve of LiF:MCP following 5-MeV alpha-particle irradiation.

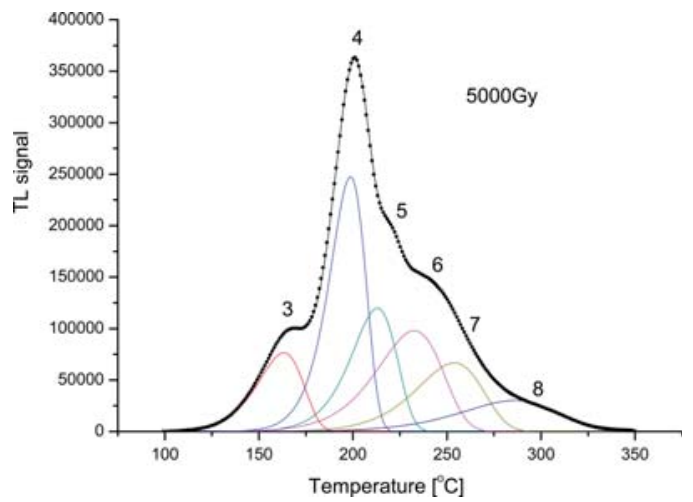

Figure 6. Glow curve of LiF:MCP following ${ }^{60} \mathrm{Co}$ gamma irradiation to a dose level of $5000 \mathrm{~Gy}$.

centre (TC)/luminescent centre (LC) giving rise to peaks 4 and composite peak $5^{(3,4)}$. Composite peak 5 is believed to arise from a TC/LC configuration based on $\mathrm{Mg}^{++} \mathrm{Li}_{\text {vac }}$ trimers (the TC) coupled to $\mathrm{Ti}(\mathrm{OH})_{\mathrm{n}}$ (the LC). Optical absorption (OA) studies ${ }^{(5)}$ have revealed that the energies of the absorption peaks for the Mg-related defects in LiF:MCP differ somewhat from those in $\mathrm{LiF}: \mathrm{Mg}, \mathrm{Ti}$ and this again suggests either different trapping structures or perturbations of those structures. Dramatic differences in the TL photon dose-response between the two materials (described below) also lead to interesting peculiarities in the dependence of the relative TL efficiency on particle energy following X ray and HCP irradiation. The dose-response of LiF:MCP enters into

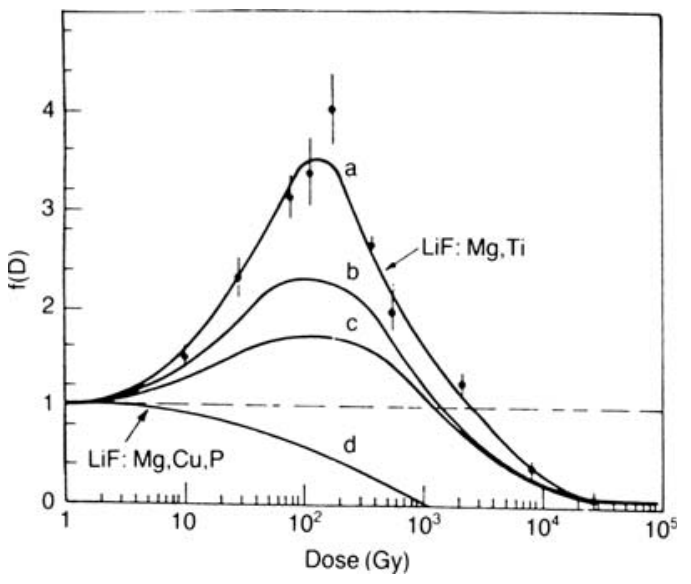

Figure 7. $f(D)$ of composite peak 5 as a function of photon energy in LiF:Mg,Ti: (a) ${ }^{60}$ Co photons, (b) $50 \mathrm{kV}_{\mathrm{p}}$ $\mathrm{X}$ rays, (c) $20 \mathrm{kV}_{\mathrm{p}} \mathrm{X}$ rays and (d) $f(D)$ of peak 4 in LiF:MCP following ${ }^{60} \mathrm{Co}$ irradiation. The values of $f(D)$ are taken from ref. (46) and do not correspond to the values shown in Table 3, which were calculated in this work.

saturation at relatively low dose levels of $\sim 1$ Gy with no observed supralinearity (Figure 7) which leads to HCP relative TL efficiencies which decrease very rapidly with increasing LET. This behaviour has been interpreted on the basis of microdosimetric track structure theories ${ }^{(6,7)}$ and the measured and TSTpredicted HCP relative efficiencies (specifically, for low-energy protons and alpha particles of $\sim 1 \mathrm{MeV}$ 
THERMOLUMINESCENCE EFFICIENCIES IN LIF: MG, CU,P

$\mathrm{amu}^{-1}$ ) in LiF:MCP are the subject of this investigation.

\section{General characteristics of LiF:MCP low-LET dose-response}

The normalised TL dose-response, $f(D)$, which is a measure of the TL efficiency, is defined as

$$
f(D)=\frac{F(D) / D}{F\left(D^{*}\right) / D^{*}}
$$

where $F(D)$ is the intensity of the TL signal at dose $D$ and $F\left(D^{*}\right)$ is the intensity of the TL signal at low dose, $D^{*}$, somewhere in the linear region of the dose-response. The gamma-induced TL doseresponse of peak 4 in LiF:MCP is linear/sublinear and does not exhibit supralinearity (increased TL efficiency: $f(D)>1$ ) unlike the situation in $\mathrm{LiF}: \mathrm{Mg}, \mathrm{Ti}$ in which composite peak 5 exhibits photon energy-dependent increased TL efficiency over the dose range from $\sim 1$ Gy to $\sim 2000$ Gy (Figure 7). The photon energy dependence of the supralinearity has been modelled in the unified interaction model (UNIM) ${ }^{(4)}$ as arising from a mixture of localised and de-localised recombination. It also deserves mention that with non-standard dopant concentrations, the dose-response of peak 4 in LiF:MCP can also exhibit supralinearity ${ }^{(8,9)}$. The linear/sublinear dose-response of LiF:MCP in standard material does not seem to show a significant dependence on photon/electron energy, although it has been reported ${ }^{(10)}$ that the macroscopic saturation parameter, $E_{\mathrm{o}}$, is equal to $243 \pm 9 \mathrm{~Gy}$ and $216 \pm 7 \mathrm{~Gy}$ following ${ }^{137} \mathrm{Cs}$ gamma $(6 \overline{61} \mathrm{keV})$ and $\overline{40}-\mathrm{keV}$ photon irradiations, respectively. $E_{\mathrm{o}}$ is defined as

$$
I=I_{\mathrm{o}}\left[1-\exp \left(-D / E_{\mathrm{o}}\right)\right]
$$

where $I$ is the signal intensity at dose $D, I_{\mathrm{o}}$ is the signal intensity at $1 \mathrm{~Gy}$ (chosen to be in the region of linear dose-response). However, these measurements were not carried out at $D>\sim 500 \mathrm{~Gy}$. Moreover, the dependence of $I / I_{\mathrm{o}}$ on dose over an extended range of dose, including high levels of dose $>1000 \mathrm{~Gy}$ cannot be adequately fitted by a single exponentially saturating function.

\section{HCP relative TL efficiencies}

The HCP relative TL efficiency, $\eta_{\mathrm{HCP}, \gamma}$ is defined as the ratio of the TL signal following HCP irradiation, $I_{\mathrm{HCB}}$ per unit energy [or per irradiated mass per unit dose $\left(D_{\mathrm{HCP}}\right)$ ] divided by the TL signal following photon/electron irradiation, $I_{\gamma}$ per unit energy (or per irradiated mass per unit dose $\left(D_{\gamma}\right)$.

$$
\eta_{\mathrm{HCP}, \gamma}=\left[\frac{I_{\mathrm{HCP}} / D_{\mathrm{HCP}}}{I_{\gamma} / D_{\gamma}}\right]=\left[\frac{I_{\mathrm{HCP}} /\left(E_{\mathrm{HCP}}\right)_{\mathrm{tot}}}{I_{\gamma} / E_{\gamma}}\right]
$$

$\left(E_{\mathrm{HCP}}\right)_{\text {tot }}$ and $E_{\gamma}$ represent the total kinetic energy absorbed in the sample following HCP and gamma/ electron irradiation, respectively. In this investigation, the authors are interested in the relative TL efficiency of low-energy HCPs which are totally absorbed in the sample. In this case:

$$
\left(E_{\mathrm{HCP}}\right)_{\mathrm{tot}}=n A E_{\mathrm{HCP}}
$$

where $n$ is the fluence $\left(\mathrm{cm}^{-2}\right), A$ is the irradiated area of the sample $\left(\mathrm{cm}^{2}\right)$ and $E_{\mathrm{HCP}}$ is the particle energy. As can be seen from eqns (3) and (4), the measurement of $\eta_{\mathrm{HCP}, \gamma}$ does not require the calculation of the range of the HCP or of the macroscopic, average dose, $D_{\mathrm{HCP}}$ In fact, the average macroscopic dose for an HCP-irradiated sample in which the inter-track dose is zero and the intra-track microscopic dose varies from MGy to zero over radial distances of $\sim 100 \mathrm{~nm}$ is a flawed concept which is difficult, if not impossible, to incorporate into any meaningful theoretical analysis.

In TST (see following sections), $\eta_{\mathrm{HCP}, \gamma}$ is calculated via integration of $f(D) D(r)$ over the entire irradiated volume constituting the HCP track where $D(r)$ is the radial dose measured from the HCP track axis. In general, the TL efficiency (the TL signal intensity per unit energy deposited in the material by the radiation field) for HCPs is lower than that for photons and decreases with decreasing particle energy (increasing LET).

The explanation for the reduced HCP TL efficiencies is straightforward and is due to full population of the available TCs and/or LCs at dose levels of several kilogray resulting in 'dose wastage'. These levels of dose in $\mathrm{LiF}: \mathrm{Mg}$, Ti occur at radial distances of less than $\sim 10 \mathrm{~nm}$. The fraction of populated TCs as a function of dose is given by

$$
\frac{n_{\mathrm{TC}}}{N_{\mathrm{TC}}}=\left(1-\exp \left[-\beta_{\mathrm{TC}} D\right]\right)
$$

where $n_{\mathrm{TC}}$ is the density of occupied TCs, $N_{\mathrm{TC}}$ is the density of available TCs at zero dose and $\beta_{\mathrm{TC}} \sim 10^{-3} \mathrm{~Gy}^{-1}$ has been measured for $\mathrm{LiF}: \mathrm{Mg}, \mathrm{Ti}$ from the dose-response of the $4 \mathrm{eV}$ OA band associated with composite peak $5^{(11,12)}$. This value of $\beta_{\mathrm{TC}}$ is not consistent with the entry into saturation of the dose-response of $\mathrm{LiF}: \mathrm{MCP}$ at a level of dose of $\sim 1-$ 10 Gy which also suggests modified trapping structures and/or different luminescent mechanisms for the main peak in the two materials. It deserves mention that even though 'dose wastage' leads to decreased TL 
efficiency, the filling of the competitive centres (CCs, believed to be electron traps in $\mathrm{LiF}: \mathrm{Mg}, \mathrm{Ti}$ ) leads to a compensating effect since the probability that a released electron will avoid an empty (active) $\mathrm{CC}$ and reach an LC actually increases. So, two opposing processes are 'at play': reduced overall TL efficiency due to 'dose wastage' and increased TL efficiency due to the de-activation (filling) of the CCs. At greater radial distances, $\sim 10 \mathrm{~nm}<r<\sim 50 \mathrm{~nm}$, depending on the distance of penetration of the alpha particle, the lower dose levels create a microscopic pattern of populated TCs, LCs and CCs corresponding to the low-LET dose-response supralinear region of increased TL efficiency in LiF:Mg,Ti. In LiF:MCP, this radial region of 'increased efficiency' is absent leading to the much smaller values of $\eta_{\mathrm{HCP}, \gamma}$. The strongly supralinear behaviour of the high-temperature TL in LiF: $\mathrm{Mg}, \mathrm{Ti}^{(13)}$ illustrates that the increased TL efficiency at intermediate radial distances from the track axis can 'overcompensate' for the decreased TL efficiency near the track axis, thus leading to values of $\eta_{\mathrm{HCP}, \gamma}>1$.

The systematics of the decreasing relative HCP TL efficiency with LET was described more than three decades ago ${ }^{(14)}$ along with microdosimetric calculations based on modified $\mathrm{TST}^{(15)}$. In these early studies, $D(r)$ for low-energy alpha particles stopping in LiF was calculated using scaling techniques, which were used to extrapolate from Monte Carlo calculations in gas and $f(D)$ was measured experimentally in both nitrogen and air-annealed samples with ${ }^{60} \mathrm{Co}$ gamma rays, $50 \mathrm{kV}_{\mathrm{p}}$ and $20 \mathrm{kV}_{\mathrm{p}} \mathrm{X}$ rays as well as ${ }^{3} \mathrm{H}$ beta rays. The latter radiation was chosen in order to approximately match the secondary electron spectrum liberated by low-energy $\left(1 \mathrm{MeV} \mathrm{amu}{ }^{-1}\right)$ alpha particles and provide better 'volume matching' of the radiation modalities in the sample. Although reasonable agreement between experiment and theory was reported, the lack of a glow curve deconvolution capability in the 1980s did not allow the isolation of peak 5 from the very complicated glow curve structure at high levels of dose, which, along with the extrapolation of $D(r)$ from the gas phase to the condensed phase, casts some doubt on the accuracy of these results and the validity of the 'reasonable agreement'. Typical recently measured values for HCP relative TL efficiencies using glow curve analysis are 0.074 and 0.174 for 3 and $7.5 \mathrm{MeV}$ alpha particles $^{(16)}$ and $0.22,0.32$ and 0.53 for $0.7-, 1.5$ - and $3-\mathrm{MeV}$ protons, respectively ${ }^{(17)}$. Due to the increasing importance of various modes of charged particle therapy and the relevance to radiation protection in space, a recent review of experimental data in these and other TL materials is also available ${ }^{(18)}$.

\section{Track structure theory}

The microscopic distribution of the energy deposition in matter is very different for gamma rays and electrons compared with HCPs. For gamma rays and electrons, energy deposition may be characterised to a good approximation as a spatially uniform low density sea of initially free electrons, holes and excitons. Although, even for gamma rays and electrons, clusters of ionisations occur at the end of the electron tracks. In contrast, electronic energy deposition by HCPs occurs in a very different manner. The immediate vicinity of an ion track is characterised by a very high instantaneous density of electrons and holes combined with the probability of fairly highenergy secondary electrons (delta rays) penetrating to much larger radial distances from the HCP track. It is the HCP velocity and mass which determine the spatial extent of electronic energy deposition about the HCP track and the partitioning of the energy among the various models of the lattice energy deposition, e.g. ionisation, exciton and plasmon formation. On the macroscopic level, gamma rays and electrons as compared with HCPs often produce different radiation end effects and one of the purposes of TST is to attempt to describe the variation in radiation end effect, in terms of the differences in the microscopic distribution of energy depositions in the two types of radiation. Thus, the radial distribution of the absorbed dose imparted by the ejected electrons around the path of the HCP determines the truck structure, and for dose rate independent systems the dose-response function of the system to electrons (or gamma rays) is coupled with the spatial distribution of the radial dose from secondary electrons to yield the response of the system to HCPs. The major premise of TST is thus that the concentration of liberated charge carriers, i.e. the radial dose $D(r)$, is the only parameter of the HCP track that governs the dependence of the relative TL properties on the type of HCP radiation.

The calculation of $D(r)$ in the condensed phase is not a trivial matter due to the lack of accurate lowenergy interaction cross sections and other issues. For example, in the intermediate energy range (around 100-200 keV amu ${ }^{-1}$ ) the mechanism of ion-matter interaction becomes more complicated due to charge exchange processes (electron capture from the ion and loss to the target atoms). Although the variation of the ion's charge state due to chargeexchange processes can be included in an approximate manner in both the Bethe ('continuous energy loss model') and dielectric theories, the energy losses associated with these processes are very difficult to treat theoretically since the validity of the Born approximation becomes questionable (the interaction can no longer be considered 'weak'). Thus, most theoretical estimates in the region of the stopping power maximum are either empirical or assume that their contribution is relatively small and can be neglected. Various analytical approximations have been described in organic media, gas and 
water ${ }^{(19,20)}$ with the result that $D(r)$ varies as $r^{-2}$. Recent Monte Carlo calculations of charged particle track structure in silicon based on an improved dielectric response model and detailed secondary electron transport simulations ${ }^{(21,}{ }^{22)}$ reveal a more complicated behaviour with $D(r)$ varying more rapidly than $r^{-2}$. Track segment Monte Carlo calculations of $D(r)$ have been carried out for low-energy protons and alpha particles in condensed phase $\mathrm{LiF}$ by Avila et al. ${ }^{(23)}$ using the Monte Carlo code TRIPOS-E as shown in Figures 8 and 9. More recent attempts at full-track Monte Carlo calculations in condensed phase LiF using $\operatorname{FLUKA}^{(24,25)}$ or GEANT4 ${ }^{(26)}$ are currently being attempted. The importance of the radial energy distribution of electron spectra (not only the dose) has also been recognised in the extension of 'average-track' TST models $^{(27)}$ but this modification has yet to be incorporated into TST calculations of TL efficiencies in the condensed phase. The Monte Carlo simulations performed with TRIPOS-E adopt several approximations, which may significantly affect $D(r)$. First of all, the secondary electron transport cut-off energy was set at $250 \mathrm{eV}$. For condensed water, energy losses $<250 \mathrm{eV}$ represent a considerable fraction of the HCPs total energy loss (roughly $50 \%$ for the HCP energies considered herein).

In some models of TST, first applied to radiobiological systems, there are no specific restrictions on the photon energy employed to measure $f(D)^{(28)}$. However, a substantial complication arises when applying TST to LiF:Mg,Ti due to the dependence of $f(D)_{\max }$ on photon/electron energy, i.e. $f(D)_{\max } \sim 3-5$ for ${ }^{60} \mathrm{Co}$ gamma rays decreasing to 1.8 for $20 \mathrm{kV}_{\mathrm{p}} \mathrm{X}$ rays (Figure 7). This dependence of $f(D)$ on photon energy is attributed to the competition between localised and de-localised recombination in the $\mathrm{UNIM}^{(4,}{ }^{29)}$ and motivated the development of modified TST (MTST) ${ }^{(14,15)}$ in which it is required that $f(D)$ be measured with photon or electron energies that create a secondary electron energy spectrum approximately matched to the HCP-generated electron spectrum.

\section{MTST-mathematical formulation}

In MTST, the relative TL efficiency is given by

$$
\begin{aligned}
& \eta_{\mathrm{HCP}, \gamma} \\
& =\eta_{\delta \gamma} \frac{W_{\gamma}}{W_{\mathrm{HCP}}} \frac{\int_{0}^{R_{\max }} \int_{0}^{r_{\max }} f_{\delta}(D) \cdot n(r, l, E) \cdot 2 \pi r \cdot \mathrm{d} r \mathrm{~d} l}{\int_{0}^{R_{\max }} \int_{0}^{r_{\max }} \int_{0}^{r_{\max }} n(r, l, E) \cdot 2 \pi r \cdot \mathrm{d} r \mathrm{~d} l}
\end{aligned}
$$

where $\eta_{\delta \gamma}$ is the relative TL response of the HCP ejected secondary electron spectrum to the gamma

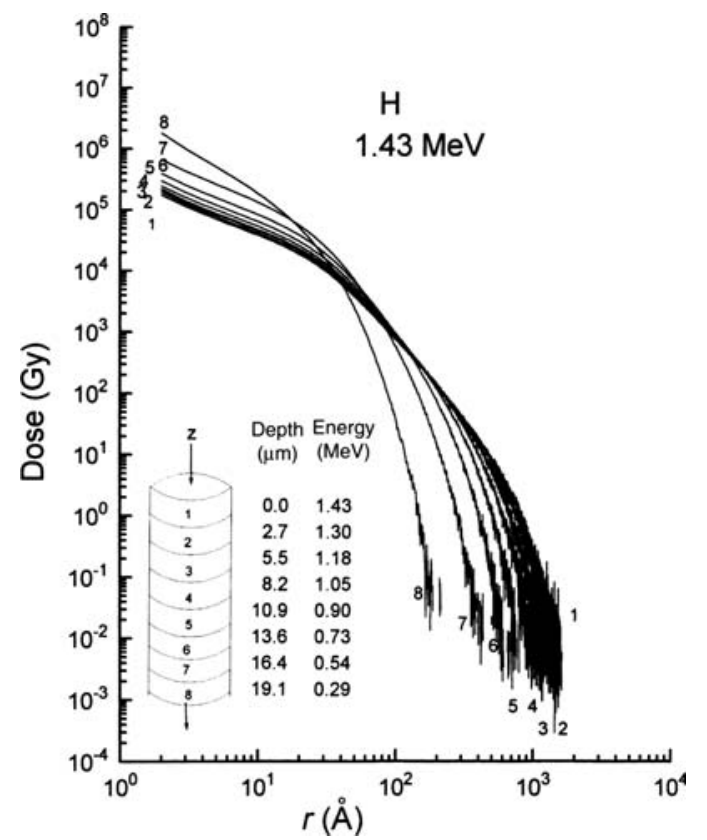

Figure 8. Track segment TRIPOS-E Monte Carlo calculations of $D(r)$ for protons from Avila et al. ${ }^{(23)}$.

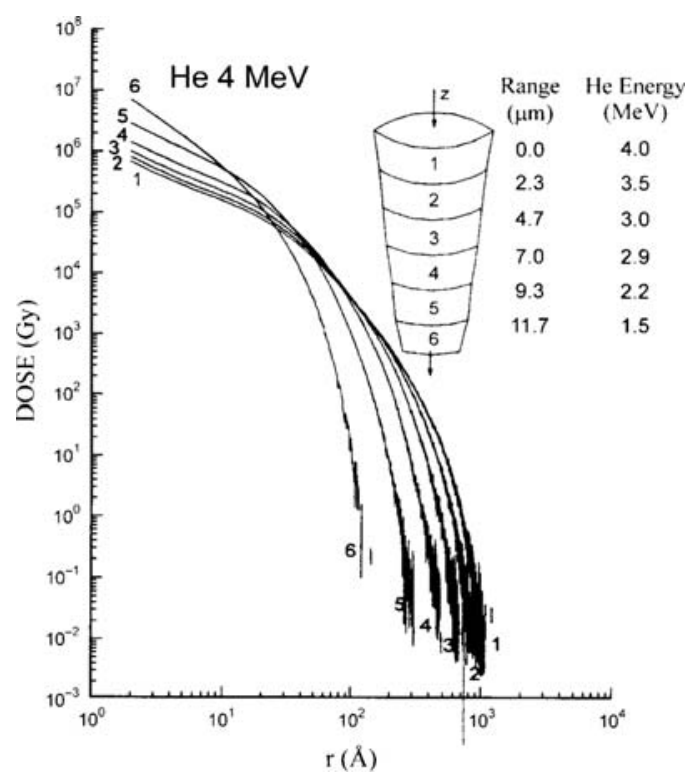

Figure 9. Track segment TRIPOS-E Monte Carlo calculations of $D(r)$ for alpha particles from Avila et al. ${ }^{(23)}$.

reference radiation which for peak 4 in $\mathrm{LiF}: \mathrm{MCP}$, under the experimental conditions described below, can be taken equal to unity. $W_{\gamma}$ and $W_{\mathrm{HCP}}$ are the average energies required to produce an electron-hole 
pair by the gamma reference radiation and HCP radiation, respectively. There is of course a certain uncertainty in the estimation of these values since there are no direct measurements in LiF. In many gases it has been demonstrated that the value of $W$ for alpha particles of energy $5.3 \mathrm{MeV}$ and protons of energy 1 $\mathrm{MeV}$ is almost always equal to or greater than the $W_{\gamma}$ value for electrons of energy $>10 \mathrm{keV}$ up to a value of $\sim 10 \%{ }^{(30)}$. The recommended value for electrons and photons in dry air is $33.97 \mathrm{eV}$. With HCPs and complex gasses $W_{\gamma}$ can vary significantly with energy and this complication is certainly present in an insulator such as LiF. In semiconductors, it is well known that $W_{\gamma}$ is empirically about 3 times the band gap energy, $E_{\mathrm{g}}$, and it has been demonstrated that this is also true for a large group of insulators ${ }^{(31)}$. The band gap in $\mathrm{LiF}$ is $\sim 13 \mathrm{eV}$, which leads to an estimate of $W_{\gamma} \sim 39 \mathrm{eV}$ different by only $\sim 15 \%$ from the value in air. A phenomenological model by Klein also yields a value of $37 \mathrm{eV}$ for $\mathrm{LiF}^{(32)}$. Based on these considerations, a value of $W_{\gamma} /$ $W_{\mathrm{HCP}}=0.90 \pm 0.1$ used herein has been guesstimated, which is slightly lower than the value of 0.94 employed in previous calculations. $R_{\max }$ and $r_{\max }$ are the maximum axial and radial distances of penetration of the charge carriers from the HCP path (in the radiation absorption stage); $f_{\delta}(D)$ is the TL dose-response measured with a test electron radiation chosen to mimic the radiation action of the HCP as closely as possible. Further information is available in other publications $^{(4,14,15,33)}$. Due to the great variability of even relative quantities in TL characteristics, it is necessary to emphasise the importance of measuring $f_{\delta}(D)$ under experimental conditions and protocol identical to the experimental measurement of $\eta_{\mathrm{HCP}, \gamma}{ }^{(34,35)}$.

\section{Microdosimetric models of TST}

Microdosimetric TST models fall essentially into two categories: the first, based on a biological interpretation of radiation action ${ }^{(28)}$ assumes the presence of a 'target volume' (for example, in biology, the DNA molecule or the cell nucleus) of variable size and the presence of 'one-hit' and 'two-hit' targets and employs the size of the volume as a parameter which can be conveniently varied in order to 'fit' the experimental data. These models lack a robust predictive ability but are capable of predicting trends as a function of particle energy ${ }^{(10)}$. The 'goodness of fit' between their predictions and the experimental measurements does not, therefore, provide a reliable test of the underlying physical assumptions of the model. In the condensed phase, target volume diameters have varied between 10 and $60 \mathrm{~nm}$ in $\mathrm{LiF}^{(7)}$. These values are much larger than even the average distances between $\mathrm{Mg}$ complexes of $\sim 2 \mathrm{~nm}$ in $\mathrm{LiF}: \mathrm{Mg}$, Ti. It may be, however, that target sizes do have some physical meaning. It has been suggested $^{(36)}$ that the 'target diameter' may correspond to the average distance of charge carrier migration in the sample before recombination, however, this idea has yet to be supported by experimental evidence or theoretical analysis. Moreover, such an average charge carrier migration distance would be dependent on the dose in systems dominated by de-localised recombination. Olko ${ }^{(37)}$ has emphasised that microdosimetric models based on radiobiological 'target theory' are phenomenological and are of limited value in describing the physical mechanisms of TL other than the initial pattern of energy deposition in agreement with Horowitz ${ }^{(38)}$ who has commented on the unrealistic conclusion that microdosimetric modelling can lead to 'a better understanding of the fundamental TL production mechanisms... and can be used to extract structure information for the various peaks, ${ }^{(39)}$.

The other category (e.g. TST and MTST) does not employ a 'site size' of variable dimensions; however, as in the case for all TST modelling, the calculation of the relative TL HCP efficiency is carried out assuming that the radiation action of the HCPs is solely due to the radiation action of the secondary electrons. Evidence against this premise is the experimental observation of enhanced production of $\mathrm{F}$ centres in $\mathrm{LiF}$ and other materials following HCP irradiation ${ }^{(40,}{ }^{41)}$. Since the minimum electron energy required to displace a light ion is between 0.1 and $0.2 \mathrm{MeV}^{(40)}$, the measurement of $f(D)$ with low-energy photons excludes the possibility of the creation of displacements and additional $\mathrm{F}$ centres and is another valid reason for the exclusive use of low photon/electron energies to generate $f(D)$ in order to determine the role of creation of defects by the HCPs. A proposed role of $\mathrm{F}$ centres in the TL mechanism of $\mathrm{LiF}: \mathrm{Mg}$, Ti has been discussed both as participators ${ }^{(42)}$ and competitors $^{(43)}$ to the luminescence recombination mechanism and has also been suggested in LiF:MCP(5). The extent of the validity of the basic assumption of TST as applied to $\mathrm{LiF}: \mathrm{Mg}, \mathrm{Ti}$ has been recently questioned. One experiment ${ }^{(4)}$ was designed to be especially sensitive to F-centre creation by the HCPs and subsequent activation by charge carrier trapping. It was found that the re-population of peak 5 TCs via $F$ band optical excitation results in a second readout alpha-particle relative TL efficiency $\sim 14$ times greater than the first readout alpha-particle relative TL efficiency and beyond the ability of TST which predicts a value of $\sim 1.5$. The second analysis $^{(33)}$ reaches the conclusion that for composite peak 5, the predictions of MTST using UNIM-calculated values of $f(D)$ for $2 \mathrm{keV}$ electrons are in agreement with 5-MeV alpha-particle relative TL efficiencies but underestimate $1.5-\mathrm{MeV}$ relative proton efficiencies by $\sim 50 \%$. Moreover, both the proton 

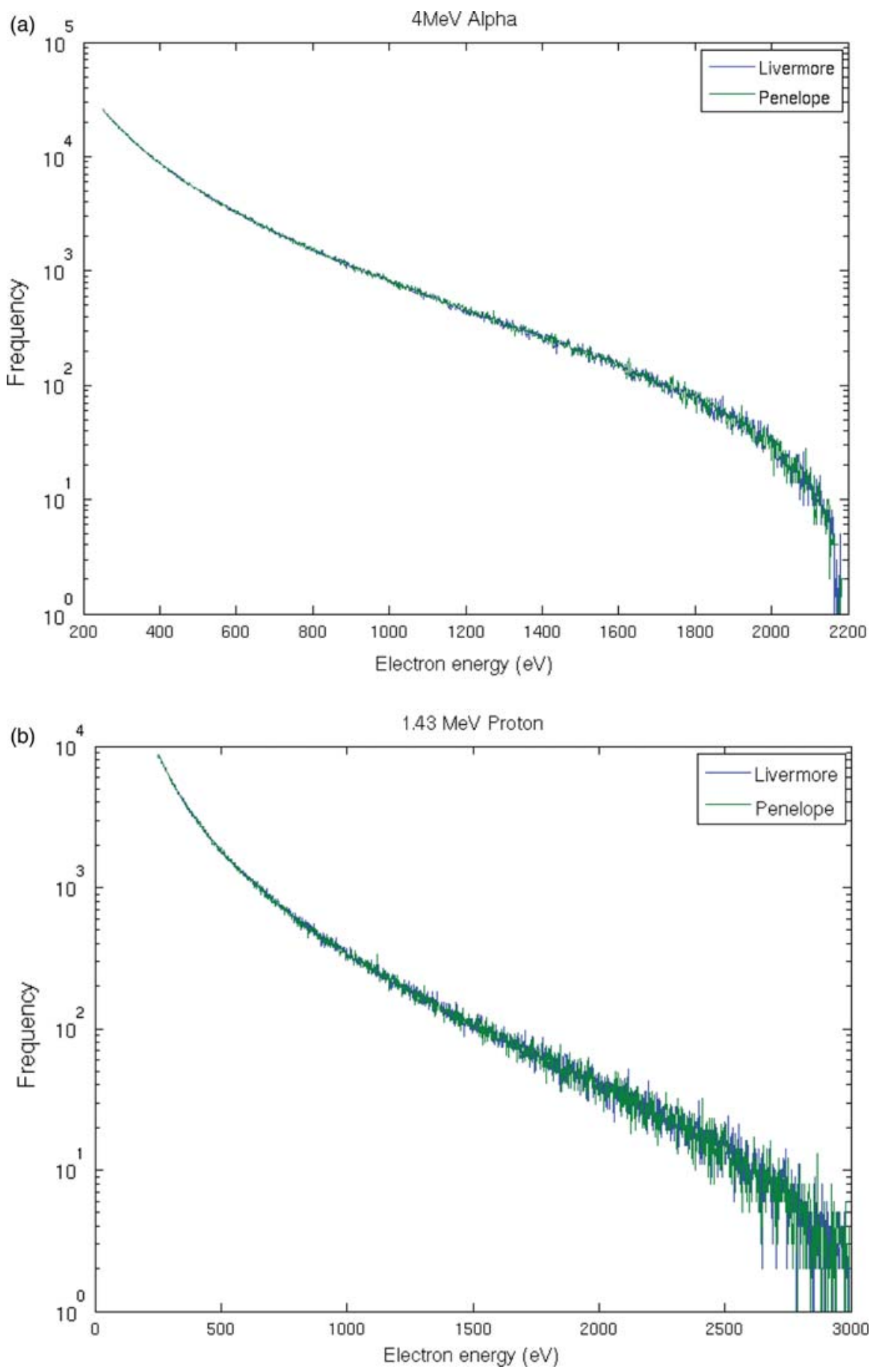

Figure 10. Comparison between the secondary electron energy spectrum following (a) 4-MeV alpha-particle irradiation and (b) 1.5-MeV protons, calculated with Geant4 using the Penelope and Livermore libraries. 
Y. S. HOROWITZ ET AL.

Table 1. Experimental measurements of $\eta_{\mathrm{HCP}, \gamma}$ in LiF:MCP.

\begin{tabular}{|c|c|c|c|c|}
\hline $\mathrm{HCP} /$ energy & $\eta_{\mathrm{HCP}, \gamma}$ & Material & Experimental details: thickness/analysis & Reference \\
\hline$\alpha / \sim 5 \mathrm{MeV}$ & $0.038(0.006)$ & $\mathrm{MCP}-7^{\mathrm{a}}$ & $0.6 \mathrm{~mm} /$ peak area & (7) \\
\hline$\alpha / 5 \mathrm{MeV}$ & $0.060(0.007)$ & MCP-N ${ }^{a}$ & $0.7 \mathrm{~mm} /$ peak area & (45) \\
\hline$\alpha / 4 \mathrm{MeV}$ & $0.050(0.006)$ & MCP-N ${ }^{a}$ & $0.7 \mathrm{~mm} /$ peak area & (45) \\
\hline$\alpha / 3 \mathrm{MeV}$ & $0.043(0.005)$ & MCP-N ${ }^{a}$ & $0.7 \mathrm{~mm} /$ peak area & (45) \\
\hline$\alpha / 1.5 \mathrm{MeV}$ & $0.034(0.005)$ & MCP-N & $0.7 \mathrm{~mm} /$ peak area & (45) \\
\hline$\alpha / 4 \mathrm{MeV}$ & $0.065(0.010)$ & GR $-200^{\mathrm{b}}$ & $0.8 \mathrm{~mm} /$ peak area $^{\mathrm{e}}$ & (46) \\
\hline$\alpha / 5 \mathrm{MeV}$ & $0.063(0.007)$ & MCP-N ${ }^{a}$ & $0.7 \mathrm{~mm} /$ peak area & (49) \\
\hline$\alpha / 2.5 \mathrm{MeV}$ & $0.035(0.015)$ & TUD $^{c}$ & - & (48) \\
\hline$\alpha / 4 \mathrm{MeV}$ & $\sim 0.09(+0.03,-0.07)$ & TUD $^{c}$ & - & (48) \\
\hline$\alpha / 4 \mathrm{MeV}$ & $\sim 0.02$ & $\mathrm{CRL}^{\mathrm{d}}$ & $98 \mu \mathrm{m} /$ peak height & (47) \\
\hline $\mathrm{p} / 1.5 \mathrm{MeV}$ & $0.15(0.02)$ & MCP-N ${ }^{a}$ & - & (49) \\
\hline $\mathrm{T} / 2.73 \mathrm{MeV}$ & $0.155(0.007)$ & MCP-N ${ }^{a}$ & $0.7 \mathrm{~mm} /$ peak area & (49) \\
\hline
\end{tabular}

${ }^{a}$ Institute of Nuclear Physics, Krakow.

${ }^{\mathrm{b}}$ Radiation Detection Works, Beijing, China.

${ }^{\mathrm{c}}$ Technische Universitat Dresden: dopant concentrations unspecified.

${ }^{\mathrm{d}}$ Central Research Laboratory, Beijing, China.

${ }^{\mathrm{e}}$ Measured by computerised glow curve deconvolution.

and alpha-particle relative TL efficiencies of the high-temperature TL (peaks 7 and 8) are underestimated by an order of magnitude.

As previously mentioned, the main experimental difficulty with the application of MTST to $\mathrm{LiF}: \mathrm{Mg}, \mathrm{Ti}$ is the requirement that the photon energy used to measure $f(D)$ creates a secondary electron spectrum matched in energy as closely as possible to the secondary electron spectrum created by the HCP slowing down. This requirement arises due to the dependence of $f(D)$ on electron/photon energy in $\mathrm{LiF}: \mathrm{Mg}, \mathrm{Ti}$. When applied to low-energy protons and alpha particles $\left(\sim 1 \mathrm{MeV} \mathrm{amu}^{-1}\right)$, the maximum photon energy required to experimentally generate $f(D)$ is $\sim 2-3 \mathrm{keV}$ (Figure 10). One approach $^{(33)}$ to estimate $f(D)$, as mentioned above, has been to extrapolate the values of $f(D)$ from higher photon/electron energies extending over the range of $8 \mathrm{keV}$ to $1.25 \mathrm{MeV}$ using the $\mathrm{UNIM}^{(4)}$. Such an extrapolation, of course, introduces a certain uncertainty in the conclusions regarding the possible failure of MTST to accurately predict the proton relative efficiencies of peak 5 as well as the relative efficiencies of the high temperature thermoluminescence. These uncertainties/difficulties should be mainly removed if one applies TST to $\mathrm{LiF}: \mathrm{MCP}$ since the photon dose-response does not seem to significantly depend on photon energy because of the lack of supralinearity in the "standard' materials. This is the motivation for the following analysis: i.e. to test the extent of the validity of the basic premise of track structure theories in a solid-state system in which the TL efficiency, $f(D)$, measured by low-LET radiation is not significantly dependent on photon/electron energy.

\section{EXPERIMENTAL MEASUREMENTS}

\section{Proton and alpha-particle relative TL efficiencies}

The results of experimental measurements of alpha particle and proton relative TL efficiencies in LiF:MCP of 'standard' levels of doping are shown in Table $1^{(7,45-49)}$. The measurements of $\eta_{\alpha, \gamma}$ on chips yield values of $\sim 0.05$ at $4-5 \mathrm{MeV}$ except for the results of Hubner et al. ${ }^{(48)}$, which are reported with very large uncertainties. This agreement is a pleasant surprise suggesting that HCP-induced TL in LiF:MCP may be less subject to differences due to material properties and variations in experimental protocols than LiF:Mg,Ti. Nonetheless, the significant difference between the two measurements of $0.038 \pm 0.007(1 \mathrm{SD})^{(7)}$ and $0.060 \pm 0.006(1 \mathrm{SD})^{(45)}$ carried out by the same group is indicative of the problems involved in accurate measurements of $\eta_{\alpha, \gamma}$. The differences in the relative intensities of the hightemperature structure illustrated in Figures 2 and 5 suggest that inclusion of the part of the hightemperature structure by readout to $240^{\circ} \mathrm{C}$ could increase the relative efficiency values for peak 4 by $\sim 5 \%$. However, the only relative efficiency of 0.065 obtained by deconvolution ${ }^{(46)}$ for GR-200 is actually the highest of the relative efficiencies - contrary to expectations. The rather low value of $0.02^{(47)}$ may be due to the use of grains of powder which are more susceptible to surface effects and possible 'dead' layers $^{(14)}$. In an additional study ${ }^{(9)}$, the values of $\eta_{\alpha, \gamma}$ for $5-\mathrm{MeV}$ alpha particles as a function of $\mathrm{Mg}$ concentration were shown to be constant at a value of $\sim 0.06$ from 0.2 to $0.8 \mathrm{M} \%$ and then increase to 0.13 at $0.05 \mathrm{M} \%$ correlated with the appearance of supralinearity in the dose-response of this material 
THERMOLUMINESCENCE EFFICIENCIES IN LIF: MG, CU,P

at higher values of $\mathrm{Mg}$ concentration. The relative efficiency studies as a function of alpha-particle energy $^{(45)}$ are especially appropriate for TST calculations since measurements of $f(D)$ were carried out to a dose level of $10000 \mathrm{~Gy}$ in the same material (see following section). In $\mathrm{LiF}: \mathrm{Mg}, \mathrm{Ti}$, typical values of $\eta_{\alpha, \gamma}$ for $4-5-\mathrm{MeV}$ alpha particles are $\sim 0.1-0.2$, which indicates a reduction in the values of $\eta_{\alpha, \gamma}$ of a factor of 2-4 for LiF:MCP. The value of $\eta_{\mathrm{py}}=0.15$ for $1.5-\mathrm{MeV}$ protons is a factor of 2 smaller than the value of 0.32 in $\mathrm{LiF}: \mathrm{Mg}, \mathrm{Ti}^{(17)}$ similar to the observed reduction in $\eta_{\alpha, \gamma}$.

\section{Low-LET LiF:MCP dose-response}

Low-dose measurements of $f(D)$ following low-LET irradiation indicate decreased TL efficiency for peak 4 beginning at $\sim 1$ Gy with reported values of $f(D)=0.91 \pm 0.01(1 \mathrm{SD})^{(49)}$ at 5 Gy in MCP-N and $f(D)=0.96$ for TLD-700H (manufactured by Thermo Electron Corporation) at $10 \mathrm{~Gy}^{(50)}$. These slight differences are to be expected in various forms of the material and different methods of analysis ${ }^{(51)}$. Accurate measurements of $f(D)$ at high dose levels require computerised glow curve deconvolution (CGCD) due to the appearance of a strongly supralinear high-temperature glow curve structure which overlaps substantially with peak 4 . CGCD has been carried out up to dose levels of $1000 \mathrm{~Gy}^{(52)}$ for GR-200 and 5000-10000 Gy ${ }^{(7,53,54)}$ for MCP-N. The previously published MCP-N data have been re-analysed in this work with a typical deconvoluted glow curve at high dose as shown in Figure 6 resulting in the values of $f(D)$ shown in Figure 11 and Table 2. In both GR-200 and MCP-N, $f(D)=0.2$ at 1000 Gy with the high-dose studies indicating that $f(D)$ decreases to $0.018 \pm 0.01 \quad(1 \quad \mathrm{SD})$ and $0.0126 \pm 0.0003$ at $5000 \mathrm{~Gy}$ and $10000 \mathrm{~Gy}$, respectively. It will be demonstrated in the following section that measurements of $f(D)$ up to these high levels of dose are necessary in order to accurately calculate $\eta_{\mathrm{HCP} \gamma}$ using eqn (6). At dose levels $>10000 \mathrm{~Gy}$, since $f(D)<0.01$ and is rapidly decreasing, the contribution to the relative HCP TL intensities becomes insignificant for LiF:MCP-N.

\section{TST calculations of $\boldsymbol{\eta}_{\boldsymbol{\alpha}, \gamma}$ and $\boldsymbol{\eta}_{\mathbf{p}, \boldsymbol{\gamma}}$}

The experimental measurements of $f(D)^{2}$ for peak 4 using ${ }^{60} \mathrm{Co}$ gamma rays up to a level of dose of $10000 \mathrm{~Gy}$ and Monte Carlo calculations of $D(r)^{(23)}$ in condensed phase $\mathrm{LiF}$ are used to calculate $\eta_{\alpha, \gamma}$ and $\eta_{\mathrm{p}, \gamma}$ [eqn (6)] as shown in Table 3. In order to demonstrate the importance of measurements of $f(D)$ in the high-dose region, Table 3 also shows values of $\eta_{\alpha, \gamma}$ and $\eta_{\mathrm{p}, \gamma}$ calculated with $f(D)^{1(7)}$ measured to dose levels of $1000 \mathrm{~Gy}$ and fitted by eqn (2) with $E_{\mathrm{o}}=178$ Gy. The differences are very

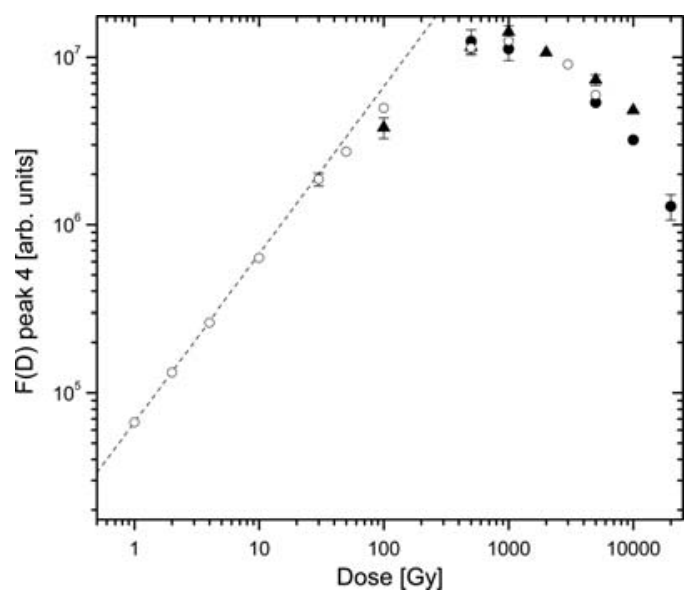

Figure 11. $f(D)$ for peak 4 in the glow curve of LiF:MCP-N measured using the computerised glow curve deconvolution and to a dose level of $20000 \mathrm{~Gy}$.

Table 2. Values of $f(D)$ used in the calculations of $\eta_{\alpha, \gamma}$ and $\boldsymbol{\eta}_{\mathbf{p}, \boldsymbol{\gamma} \text {. }}$

\begin{tabular}{lc} 
Dose (Gy) & $f(D)$ \\
\hline 1 & 1 \\
2 & $0.99(0.03)$ \\
4 & $0.98(0.04)$ \\
10 & $0.948(0.04)$ \\
30 & $0.929(0.08)$ \\
50 & $0.817(0.008)$ \\
100 & $0.744(0.05)$ \\
500 & $0.34(0.02)$ \\
1000 & $0.189(0.01)$ \\
3000 & $0.045(0.025)$ \\
5000 & $0.018(0.01)$ \\
10000 & $0.0126(0.003)$ \\
20000 & $0.0025(0.001)$
\end{tabular}

Below $D=1$ Gy: $f(D)=1$.

substantial. Comparison of the theoretical values using $f(D)^{2}$ are in improved agreement but still significantly lower than the experimental values. The error in the theoretical estimates due to the errors in $f(D)$ shown in Table 2 is of the order of $10 \%$. The calculated values do predict a greatly reduced relative efficiency to protons and alpha particles as well as the trend to decreasing relative efficiency with decreasing alpha-particle energy (increasing LET) and this can be considered a partial success of the theory. On the other hand, the calculated values consistently and significantly underestimate the measured relative TL efficiencies. For the alpha particles, the theoretical values are $32,48,70$ and $88 \%$ lower 
Y. S. HOROWITZ ET AL.

Table 3. TST calculations of $\eta_{\alpha, \gamma}$ and $\eta_{p, \gamma}$ of peak 4 in LiF:Mg,Cu,P.

\begin{tabular}{|c|c|c|c|c|c|c|c|}
\hline \multicolumn{4}{|l|}{ Alpha particles } & \multicolumn{4}{|c|}{ Protons } \\
\hline \multirow{2}{*}{$\begin{array}{l}\text { Energy }(\mathrm{MeV}) \\
\text { track segment }\end{array}$} & \multicolumn{3}{|c|}{$\eta_{\alpha, \gamma}$} & \multirow{2}{*}{$\begin{array}{l}\text { Energy }(\mathrm{MeV}) \\
\text { track segment }\end{array}$} & \multicolumn{3}{|c|}{$\eta_{\mathrm{p}, \gamma}$} \\
\hline & $f(D)^{1}$ & $f(D)^{2}$ & & & $f(D)^{1}$ & $f(D)^{2}$ & \\
\hline 4.95 & 0.0063 & 0.1039 & & 1.43 & 0.1300 & 0.1800 & \\
\hline 4.00 & 0.0450 & 0.0756 & & 1.3 & 0.1087 & 0.1540 & \\
\hline 3.5 & 0.0329 & 0.0566 & & 1.18 & 0.1040 & 0.1462 & \\
\hline 3.00 & 0.0204 & 0.0367 & & 1.05 & 0.0869 & 0.1264 & \\
\hline 2.20 & 0.0040 & 0.0077 & & 0.9 & 0.0630 & 0.0965 & \\
\hline \multirow[t]{3}{*}{1.5} & 0.0012 & 0.0027 & & 0.73 & 0.0393 & 0.0950 & \\
\hline & & & & 0.54 & 0.0160 & 0.0294 & \\
\hline & & & & 0.29 & 0.0047 & 0.0097 & \\
\hline \multirow{2}{*}{$\begin{array}{l}\text { Energy weighted } \\
\text { averages }(\mathrm{MeV})\end{array}$} & \multicolumn{3}{|c|}{$\eta_{\alpha, \gamma}$} & Energy weighted & \multicolumn{3}{|c|}{$\eta_{\mathrm{p}, \gamma}$} \\
\hline & $f(D)^{1}$ & $f(D)^{2}$ & $\begin{array}{l}\text { Experimental } \\
\text { measurements }\end{array}$ & & $f(D)^{1}$ & $f(D)^{2}$ & $\begin{array}{l}\text { Experimental } \\
\text { measurements }\end{array}$ \\
\hline 4.95 & 0.023 & 0.041 & 0.060 & 1.43 & 0.056 & 0.087 & 0.15 \\
\hline 4.00 & 0.015 & 0.026 & 0.050 & & & & \\
\hline 3.00 & 0.0070 & 0.013 & 0.043 & & & & \\
\hline 1.5 & 0.0012 & 0.0041 & 0.034 & & & & \\
\hline
\end{tabular}

than the experimental values at the energies of 4.95 , 4,3 and $1.5 \mathrm{MeV}$, respectively. The trend of $\eta_{\alpha, \gamma}$ with decreasing energy is especially poorly predicted. Experimentally, $\eta_{\alpha, \gamma}$ decreases by a factor of 2 from 4.95 to $1.5 \mathrm{MeV}$ - the theoretical values decrease by an order of magnitude! For the protons, the theoretical value is $42 \%$ too low. These differences certainly require an attempt at explanation and further investigations are discussed below.

\section{Measurements of $f(D)$ at high levels of dose}

Figure 11 illustrates the spread of results measured in different experiments by the Polish group. Above $\sim 1000 \mathrm{~Gy}$, these differences lead to $\sim 50 \%$ deviations in $f(D)$ which could significantly affect the values of $\eta_{\alpha, \gamma}$ and $\eta_{\mathrm{p}, \gamma}$ especially if the experimental measurements of $\eta_{\alpha, \gamma}$ and $\eta_{\mathrm{p}, \gamma}$ and $f(D)$ were carried out with different protocols. As shown in Table 3, the differences in the relative TL efficiencies calculated using $f(D)^{1}$ (without the contribution from high dose levels) and $f(D)^{2}$ (with the contribution from high levels of dose up to $20000 \mathrm{~Gy}$ ) are very substantial.

\section{The dependence of $f(D)$ on photon energy}

The effects of saturation and/or radiation damage leading to reduced efficiency $[(f(D)<1]$ may be shifted to higher/or lower levels of dose as a function of photon energy. As previously mentioned, the dose-response of LiF:MCP-N measured to $\sim 500$ Gy using ${ }^{60} \mathrm{Co}$ gamma rays and $40 \mathrm{keV} \mathrm{X}$ rays resulted in $E_{\mathrm{o}}=243 \pm 9$ and $216 \pm 7 \mathrm{~Gy}$, respectively, indicating a later entry into reduced values of $f(D)$ with decreasing photon energy. If this trend were to continue to lower photon energies of a few kiloelectron volt, it could also lead to a significant increase in the theoretical values of $\eta_{\alpha, \gamma}$.

\section{Photon self-attenuation in the sample}

LiF:MCP pellets are sintered from polycrystalline powder and are considerably less transparent to TL photons than $\mathrm{LiF}: \mathrm{Mg}, \mathrm{Ti}$ cut or extruded from monocrystals. The attenuation of TL light created in the LiF:MCP sample will be dependent on the type of radiation since photons irradiate uniformly, whereas $5-\mathrm{MeV}$ alpha particles are absorbed in a layer of $\sim 0.02 \mathrm{~mm}$ thickness. The TL output for alpha particles will, therefore, be dependent on the orientation of the irradiated sample with regard to the photomultipler ${ }^{(46,55)}$. The problems in the calculations of light transport and attenuation following irradiation by various radiation modalities have been discussed elsewhere ${ }^{(55,56)}$. The assumptions involved in the calculation of the self-attenuation concern (1) the reflection coefficient of the planchet, (2) the spatial distribution of TL photons created in the sample, and (3) the vector properties of the photon fluence from point of creation. Analytical calculations, however, have been based on simple one-dimensional attenuation following Lambert's law:

$$
I=I_{\mathrm{o}} \mathrm{e}^{-\mu x}
$$


where $\mu$ is the light absorption coefficient, $x$ is the thickness of absorbing material and $I$ and $I_{\mathrm{o}}$ are the light intensities before and after crossing the layer, respectively. Measurements of $\mu$ for sintered LiF:MCP have yielded good agreement: $1.65 \mathrm{~mm}^{-1(46)}$ and $1.69 \pm 0.05 \mathrm{~mm}^{-1(56)}$ in GR-200 and MTS-N, respectively. However, these experiments have reported contradictory measurements of the reflection coefficient of the platinum planchet, with values of 0.96 in a Harshaw 3500 reader $^{(46)}$ and $0.19 \pm 0.04$ in an RA-94 TL reader (Mikrolab, Krakow) ${ }^{\left(5 \frac{1}{6}\right)}$. An intermediate value of 0.45 for a stainless steel planchet covered with a un-specified non-reflecting substance has also been reported ${ }^{(57)}$. The Handbook of Chemistry and Physics ${ }^{(5)}$ quotes a reflection coefficient of 0.62 for incandescent light incident on a specular surface of platinum as well as a coefficient of absorption of 0.1 for solar radiation incident on highly polished platinum ${ }^{(51)}$. Horowitz and Stern ${ }^{(46)}$ calculated self-absorption factors of 0.35 and 0.53 for gamma irradiated and $5-\mathrm{MeV}$ alpha-irradiated samples (irradiated side facing the photomultiplier), whereas Bilski et al. ${ }^{(56)}$, using different assumptions (no reflection from the planchet) arrived at 0.7 and 0.98 , respectively. Serendipitously, these values correspond to correction factors of $0.66(=0.35 / 0.53)$ and $0.72(=0.7 / 0.98)$, respectively, to account for the different self-absorption of the two types of radiation, a difference of only $\sim 10 \%$. However, the differences in the calculated self-absorption factors for each radiation modality in the two sets of measurements, coupled with the uncertainties associated with the one-dimensional application of eqn (7) and the great variations in the estimated reflection coefficient of the planchet, indicate that the error introduced in the calculation of the relative TL efficiencies is at least $10 \%$ may be significantly greater.

\section{Monte Carlo calculations of $D(r)$}

Because of the scarcity of electron cross sections at ultra-low energies in condensed phase LiF below approximately kiloelectron volt, it is difficult to determine the accuracy of the Monte Carlo estimates of $D(r)^{(23)}$. In order to demonstrate the possible effect of $D(r)$ on the MTST-determined values of the relative efficiencies, $\eta_{\alpha, \gamma}$ for peak 5 in LiF:Mg,Ti using values of $D(r)$ calculated analytically ${ }^{(59)}$ have been determined and these are 20-30\% lower than those calculated using the TRIPOS-E Monte Carlo calculations. In addition, there have been no calculations of $\eta_{\alpha, \gamma}$ and $\eta_{\mathrm{p}, \gamma}$ which take into account the energy distribution of the HCP-liberated secondary electron spectrum as a function of position in the track. These have yet to be calculated by Monte Carlo or any other means and may also significantly affect the final result. As previously mentioned, in the TRIPOS-E calculations, the secondary electron transport cut-off energy was set at $250 \mathrm{eV}$, which includes roughly $50 \%$ for the HCP energies considered herein. Moreover, since electrons of $\sim 250 \mathrm{eV}$ energy have penetration distances of several nanometres and given the very steep gradient of $D(r)$, it is very likely that the inclusion of electrons $<250 \mathrm{eV}$ could significantly influence $D(r)$. In addition, TRIPOS-E uses the scheme proposed by Fitting and Reinhard ${ }^{(60)}$ which treats low-energy losses (defined as those with energy transfer $<100 \mathrm{eV}$ ) in e-e inelastic collisions using dielectric theory and the so-called optical approximation wherein the dielectric function is assumed to be independent of momentum. However, this is well known to be a satisfactory approximation only for high-energy electrons. In the TRIPOS-E calculations of $D(r)$, the simulation threshold for electron transport was set at $50 \mathrm{eV}$, which is unjustified since the optical approximation is invalid in this energy range. In fact, an improved version is available ${ }^{(61)}$ in which the dielectric function was made to be momentum dependent. It may be therefore that the results of the TRIPOS-E calculations could be significantly improved over the first $10 \mathrm{~nm}$ from the track axis if more accurate models for the transport of low-energy electrons are incorporated.

\section{CONCLUSION}

TST calculations of $\eta_{\alpha, \gamma}$ and $\eta_{\mathrm{p}, \gamma}$ in LiF:MCP are consistently and significantly lower than the experimentally measured values. However, the uncertainties in the experimental measurements of $\eta_{\alpha, \gamma}$ and $\eta_{\mathrm{p}, \gamma}$, the uncertainties in the measurement of $f(D)$ at high levels of dose with the appropriate radiation fields of low LET and the possible uncertainties in the calculation of $D(r)$ are substantial. The calculations of $D(r)$ especially require additional attention due to the two approximations employed. That is (1) alpha particle and proton energy losses $<250 \mathrm{eV}$, which represent a significant fraction of the total losses are assumed to be deposited locally (right on the track) and (2) the energy loss model used for electron transport from $\sim 200 \mathrm{eV}$ down to the simulation threshold of $50 \mathrm{eV}$ is not justified from a collision physics perspective. Both of these approximations may affect $D(r)$ over distances of tens of nanometre and may significantly affect the level of dose in the first $10 \mathrm{~nm}$ from the track axis. The observation that the discrepancy between experimental measurements and TST predictions increases from 23 to $87 \%$, with decreasing energy is consistent with the fact that with decreasing ion energy the secondary electron spectrum is dominated more and more by low-energy electrons and can be taken as evidence for the importance of improving the low-energy electron transport in the calculations 


\section{Y. S. HOROWITZ ET AL.}

of $D(r)$. In addition, full-track Monte Carlo calculations are indicated since high-energy electrons generated from ion-atom ionisation collisions exhibit strong forward scattering compared with low-energy electrons (which are more isotropic). These forward scattered electrons may contribute significantly to the radial dose in subsequent track segments of the ion track, which could result in the extension of the radial dose of subsequent track segments (associated with lower ion energies) to larger radial distances, thereby decreasing the discrepancy between theory and experiment. In addition, nuclear collisions are increasingly important with decreasing ion energy, which could be an additional factor in the observed discrepancy between theory and experiment with decreasing alpha-particle energy. It appears, therefore, that it is premature to arrive at a definite conclusion concerning the validity of basic premise of TST, although the deviations between theory and experiment appear very substantial. Such a conclusion must await more careful and sophisticated calculations/measurements of the above quantities so as to reduce and carefully assess the associated errors.

\section{REFERENCES}

1. Horowitz, Y. S. LiF: $\mathrm{Mg}, \mathrm{Ti}$ versus $\mathrm{LiF}: \mathrm{Mg}, \mathrm{Cu}, \mathrm{P}$ :The competition heats up. Radiat. Prot. Dosim. 47, 135-141 (1993).

2. Bilski, P. Lithium fluoride: from LiF:Mg,Ti to LiF: $M g, C u, P$. Radiat. Prot. Dosim. 100, 199-206 (2002).

3. Weizman, Y., Horowitz, Y. S. and Oster, L. Optically induced conversion of glow peaks 4 and 5 in $\mathrm{LiF}: \mathrm{Mg}, \mathrm{Ti}$ due to localised and de-localised recombination mechanisms. J. Lumin. 87, 552-554 (2000).

4. Horowitz, Y. S. Theories of dose response in $T L$ systems. In: Microdosimetric Response of Physical and Biological Systems to low and high LET radiation. Horowitz, Y. S., Ed. Elsevier Publ. Co., pp. 75-202 (2006).

5. McKeever, J., Macintyre, D., Taylor, S. R., McKeever, S. W. S., Horowitz, A. and Horowitz, Y. S. Diffuse reflectance and transmission measurements on LiF: $\mathrm{Mg}, \mathrm{Cu}, \mathrm{P}$ and single crystals. Radiat. Prot. Dosim. 47, 123-127 (1993).

6. Horowitz, Y. S. and Olko, P. The effects of ionisation density on the thermoluminescent response (efficiency) of LiF: Mg, Ti and LiF: $\mathrm{Mg}, \mathrm{Cu}, \mathrm{P}$ detectors. Radiat. Prot. Dosim. 109, 331-348 (2004).

7. Olko, P., Bilski, P., El-Faramawy, N. A., Goksu, H. Y., Kim, J. L., Kopec, R. and Waligorski, M. P. R. On the relationship between dose-, energy- and LET-response of thermoluminescent detectors. Radiat. Prot. Dosim. 119, 15-22 (2006).

8. Cai, G. G., Bestion, N., Wang, S. S., Shen, W. X., Delard, R., Volpiliere, J., Fesquet, J. and Gasiot, J. Dose response of the individual peak for $\mathrm{LiF}: \mathrm{Mg}, \mathrm{Ti}$ (TLD-100) and LiF:Mg,Cu,P (GR-200A) TL materials at the photon energies of 30, 104 and 1250 keV. Radiat. Prot. Dosim. 65, 213-215 (1996).

9. Bilski, P., Budzanowski, M., Olko, P. and Waligorski, M. P. R. Influence of concentration of magnesium on the dose response and LET dependence of TL efficiency in LiF: $\mathrm{Mg}, \mathrm{Cu}, \mathrm{P}(\mathrm{MCP}-\mathrm{N})$ detectors. Radiat. Meas. 29, 355-359 (1998).

10. Waligorski, M. P. R., Olko, P., Bilski, P., Budzanowski, M. and Niewiadomski, T. Dosimetric characteristics of LiF: Mg, Cu,P phosphors - a track structure Interpretation. Radiat. Prot. Dosim. 47, 53-58 (1993).

11. McKeever, S. W. S. Optical absorption and luminescence in TLD-100. J. Appl. Phys. 56, 2883-2889 (1984).

12. Issa, N., Horowitz, Y. S. and Oster, L. Optical absorption in LiF: $\mathrm{Mg}$, Ti and its relationship to thermoluminescence and thermoluminescence dose response. Radiat. Meas. 33, 491-496 (2001).

13. Livingstone, J., Horowitz, Y. S., Oster, L., Datz, H., Lerch, M., Rosenfeld, A. and Horowitz, A. Experimental investigation of the $100 \mathrm{keV} x$-ray dose response of the high temperature thermoluminescence in LiF:Mg,Ti (TLD-100): theoretical interpretation using the Unified Interaction Model. Radiat. Prot. Dosim. 138, 320-333 (2010).

14. Horowitz, Y. S. The theoretical and microdosimetric basis of thermoluminescence and applications to dosimetry. Phys. Med. Biol. 26, 765-824 (1981).

15. Kalef-Ezra, J. and Horowitz, Y. S. Heavy charged particle thermoluminescence dosimetry: track structure theory and experiments. Int. J. Appl. Radiat. Isot. 33, 1085-1100 (1982).

16. Rodríguez-Villafuerte, M., Buenfil, A. E., Gamboa deBuen, I., Ruiz-. Trejo, C., Brandan, M. E., Yossian, D., Satinger, D. and Horowitz, Y. S. Study of the response of LiF: Mg, Ti to 3 and $7.5 \mathrm{MeV}$ helium ions:measurements and interpretation. Nucl. Instrum. Methods B 160, 377-386 (2000).

17. Gamboa deBuen, I., Ruiz, C., Oliver, A., López, K. and Brandan, M. E. Supralinear response and efficiency of LiF: Mg,Ti to 0.7, 1.5 and $3 \mathrm{MeV}$ protons. Nucl. Instrum. Methods B 183, 487-496 (2001).

18. Berger, T. and Hajek, M. TL efficiency-overview and experimental results over the years. Radiat. Meas. 43, 146-156 (2008).

19. Fain, J., Monnin, M. and Montret, M. Spatial energy distribution around heavy-ion path. Radiat. Res. 57, 379-389 (1974).

20. Chen, J. and Kellerer, A. M. Calculation of radial dose distributions for heavy ions by a new analytical approach. Radiat. Prot. Dosim. 70, 55-58 (1997).

21. Akkerman, A. and Barak, J. Ion track structure and its effects in small size volumes of silicon. IEEE Trans. Nucl. Sci. 49, 3022-3031 (2002).

22. Emfietzoglou, D., Akkerman, A. and Barak, J. New Monte Carlo calculations of charged particle track structure in Silicon. IEEE Trans. Nucl. Sci. 51, 2872-2879 (2004).

23. Avila, O., Gamboa-deBuen, I. and Brandan, M. E. Study of the energy deposition in LiF by heavy charged particle irradiation and its relationship to the thermoluminescent efficiency of the material. J. Phys. D Appl. Phys. 32, 1175-1181 (1999). 


\section{THERMOLUMINESCENCE EFFICIENCIES IN LIF: MG, CU,P}

24. Mark, S., Oster, L., Horowitz, Y. S., Satinger, D., Haviv, Y. and Orion, I. Fluka Monte Carlo calculations of complete track helium ions and proton radial dose profiles in LiF. In: 15th International Conference on Solid State Dosimetry, Delft, Holland (2007).

25. Mark, S., Horowitz, Y. S., Oster, L. and Fuks, E. Monte Carlo Calculations of 3-D dose distributions following alpha particle irradiation in condensed phase LiF. In: 11th Neutron and Ion Dosimetry Symposium, Capetown (2009).

26. Livingstone, J., Guatelli, S., Horowitz, Y. S. and Rosenfeld, A. B. Nanodosimetric study of heavy charged particle track structure in lithium fluoride using Monte Carlo simulation. In: International Workshop in Monte Carlo Computational Methods in Radiation Track Simulation and Applications in Physical, Biological and Medical Sciences, Stockholm, MC (2010).

27. Cucinotta, F. A., Katz, R. and Wilson, J. W. Radial distribution of electron spectra from high-energy ions. Radiat. Environ. Biophys. 37, 259-265 (1998).

28. Katz, R. Track structure theory in radiobiology and radiation protection. Nucl. Tracks 2, 1-28 (1978).

29. Horowitz, Y. S. Theory of thermoluminescence gamma dose response. Nucl. Instrum. Methods B 184, 68-84 (2001).

30. ICRU. Average energy required to produce an ion pair. ICRU Report 31. ICRU Publications (1979).

31. Alig, H. C. and Bloom, S. Electron-hole-pair creation energies in Semiconductors. Phys. Rev. Letts. 35, 1522-1525 (1975).

32. Klein, C. A. Bandgap dependence and related features of radiation ionization energies in semiconductors. J. Appl. Phys. 19, 2029-2038 (1968).

33. Horowitz, Y., Fuks, E., Datz, H., Oster, L., Livingstone, J. and Rosenfeld, A. Mysteries of LiF$T L D$ response following high ionisation density irradiation: nanodosimetry and track structure theory, dose response and glow curve shapes. Radiat. Prot. Dosim. 145, 356-372 (2011).

34. Avila, O., Rodriguez-Villafuerte, M., Gamboa-deBuen, I., Aviles, P., Estrada, D., Buenfil, A. E., Ruiz-Trejo, C., Brandan, M. E. and Horowitz, Y. S. On the correct measurement of relative $H C P$ to gamma TL efficiencies. Radiat. Prot. Dosim. 100, 87-90 (2002).

35. Avila, O. and Brandan, M. E. Influence of $f(D)$ on modified track structure theory efficiency calculations. Radiat. Prot Dosim. 100, 163-166 (2002).

36. Horowitz, Y. S. The average distance between $M g$-based trapping structures in LiF:Mg, Ti and LiF: $\mathrm{Mg}, \mathrm{Cu}, \mathrm{P}$ and the relevance to microdosimetry. Radiat. Prot. Dosim. 82, 51-54 (1999).

37. Olko, P. Microdosimetric modeling of the relative efficiency of thermoluminescent materials. Radiat. Meas. 38, 781-786 (2004).

38. Horowitz, Y. S. Comments on observation of enhanced efficiency in the excitation of ion-induced $\mathrm{LiF}: \mathrm{Mg}, \mathrm{Ti}$ thermoluminescent peaks. Lett. Ed., Radiat. Prot. Dosim. 124, 411-416 (2007).

39. Massillon, G., Gamboa-deBuen, I. and Brandan, M. E. Observation of enhanced efficiency in the excitation on ion-induced LiF:Mg,Ti thermoluminescent peaks. J. Appl. Phys. 100, 103521-103527 (2006).
40. Levy, P. W. A brief survey of radiation effects applicable to geology problems, Ch. 2.2. In: Thermoluminescence of Geological Materials. Academic Press, pp. 25-38 (1968).

41. Perez, A., Balanza, E. and Dural, J. Experimental study of point-defect creation in high-energy heavy ion tracks. Phys. Rev. B41, 3943-3950 (1990).

42. Mayhugh, M. R. Color centers and the thermoluminescence mechanism in LiF. J. Appl. Phys. 41, 4767-4782 (1970).

43. Flerov, V. I. and Flerov, A. V. The role of $F$ centers in the thermoluminescence of lithium fluoride. Radiat. Prot. Dosim. 65, 105-108 (1996).

44. Weiss, D., Horowitz, Y. S. and Oster, L. Ionisation density effects following F-centre optical excitation in LiF: Mg,Ti (TLD-100): analysis via track structure theory. J. Phys. D Appl. Phys. 42, 85113-85124 (2009).

45. Bilski, P., Olko, P., Burgkhardt, B., Piesch, E. and Waligorski, M. P. R. Thermoluminescence efficiency of LiF: $\mathrm{Mg}, \mathrm{Cu}, \mathrm{P}$ (MCP-N) detectors to photons, beta electrons, alpha particles and thermal neutrons. Radiat. Prot. Dosim. 55, 31-38 (1994).

46. Horowitz, Y. S. and Stern, N. Relative thermoluminescent efficiency of $\mathrm{LiF}: \mathrm{Mg}, \mathrm{Cu}, \mathrm{P}$ to alpha particles. Radiat. Prot. Dosim. 33, 287-290 (1990).

47. Pradhan, A. S. and Bhatt, R. S. Thermoluminescent response of $\mathrm{LiF}: \mathrm{Mg}, \mathrm{Cu}, \mathrm{P}$ and $\mathrm{LiF}-\mathrm{TLD}-100$ to thermal neutrons, ${ }^{241} \mathrm{Am}$ alphas and gammas. Radiat. Prot. Dosim. 27, 185-188 (1989).

48. Hubner, K., Fellinger, J. and Schmidt, P. TL response of $\mathrm{LiF}: \mathrm{Mg}, \mathrm{Cu}, \mathrm{P}$ to heavy charged particles. In: Proceedings of the 22nd International Symposium on Radiation Protection Dosimetry, Gaussig (1990).

49. Bilski, P., Budzanowski, M., Hoffman, W., Molokanov, A., Olko, P. and Waligorski, M. P. R. Investigation of efficiency of thermoluminescence detectors for particle therapy beams. Radiat. Prot. Dosim. 70, 501-504 (1997).

50. Velbeck, K. J., Luo, L. Z., Ramlo, M. J. and Rotunda, J. E. The dose response of Harshaw TLD-700H. Radiat. Prot. Dosim. 119, 255-258 (2006).

51. Datz, H., Horowitz, Y. S., Oster, L. and Margaliot, M. Dose threshold for TL dose response non-linearity, dependence on the method of data analysis: its not only the data. Radiat. Meas. doi:10.1016/J.radmeas.2011. 05.026

52. Horowitz, Y. S. and Shachar, B. B. Thermoluminescent $\mathrm{LiF}: \mathrm{Cu}, \mathrm{Mg}, P$ for gamma ray dosimetry in mixed fast neutron radiation fields. Radiat. Prot. Dosim. 23, 401-404 (1988).

53. Bilski, P., Olko, P., Puchalska, M., Obryk, B., Waligorski, M. P. R. and Kim, J. L. High-dose characterisation of different LiF phosphors. Radiat. Meas. 42, 582-585 (2007).

54. Bilski, P., Obryk, B., Olko, P., Mandowska, E., Mandowski, E. and Kim, J. L. Characteristics of LiF: $M g, C u, P$ thermoluminescence at ultra-high dose range. Radiat. Meas. 43, 315-318 (2008).

55. Olko, P. Micrododosimetric interpretation of photon energy response in TL systems, Ch. 2. In: Microdosimetric Response of Physical and Biological Systems to Low and High LET Radiation. Horowitz, Y.S. Ed. Elsevier Publ. Co., pp. 203-251 (2006). 


\section{Y. S. HOROWITZ ET AL.}

56. Bilski, P. and Budzanowski, M. Self-attenuation of TL light comparison of different experimental techniques. Radiat. Meas. 33, 679 (2001).

57. Bartlett, D. T. and Edwards, A. A. The light conversion efficiency of TLD-700 to ${ }^{60}$ Co gamma rays. Phys. Med. Biol. 24, 1276 (1979).

58. Weast, R. C. (ed.). Handbook of Chemistry and Physics, 69th edn. E404-405. CRC Press (19881989).
59. Montret, M. Distribution Spatiale de L'Energie depose par des ions Energetiques dans les Mileux Condenses. Thesis. Universite de Clermont-Ferrand, France (1980).

60. Fitting, H.-J. and Reinhardt, J. Monte Carlo simulation of keV electron scattering in solid targets. Phys. Stat. Sol.(a). 88, 245-259 (1985).

61. Kuhr, J.-Ch. and Fitting, H.-J. Monte Carlo simulation of low energy electron Scattering in solids. Phys. Stat. Sol.(a). 172, 433-449 (1999). 